\title{
Evaluating the effect of increased physical activity in lower secondary school adolescents: The study protocol for the School in Motion (ScIM) study - a cluster-randomized controlled trial.
}

Elin Kolle ( $\nabla$ elin.kolle@nih.no)

Norges idrettshogskole https://orcid.org/0000-0003-4134-6887

Runar Barstad Solberg

Norges idrettshogskole

May Grydeland

Norges idrettshogskole

Reidar Säfvenbom

Norges idrettshogskole

Sigmund Alfred Anderssen

Norges idrettshogskole

Ulf Ekelund

Norges idrettshogskole

Sveinung Berntsen

Universitetet i Agder

Geir Kåre Resaland

Hogskulen pa Vestlandet - Campus Sogndal

Sindre M. Dyrstad

Universitetet i Stavanger

Jostein Steene-Johannessen

Norges idrettshogskole

Research article

Keywords: Cluster-randomized trial, adolescents, school-based, physical activity, accelerometers, cardiorespiratory fitness, mental health, academic performance, learning environment

Posted Date: January 13th, 2020

DOI: https://doi.org/10.21203/rs.2.20653/v1 
License: (c) (i) This work is licensed under a Creative Commons Attribution 4.0 International License. Read Full License 


\section{Abstract}

Background: Participation in regular physical activity (PA) is important for both physical and mental health, and positive associations have also been reported between PA and academic performance. However, PA levels decline markedly during adolescence. School in motion (ScIM) is a school-based PA intervention carried out over one school year, in a sample of 14-year-old girls and boys. The primary aim was to investigate whether two extra hours of PA weekly lead to increases in the adolescents' accelerometer assessed PA levels. Secondary aims were to investigate the intervention effects on time spent in PA of different intensities, muscle strength, cardiorespiratory fitness, mental health, academic performance and learning environment. ffig

Methods \& design: This is a multicenter, school-based, three-arm cluster randomized controlled trial (RCT) recruiting ninth graders from lower secondary schools in Norway. A total of 2084 14-year-olds from 29 schools were included, yielding a participation rate of $76 \%$. Schools (clusters) were randomly assigned to one of three study arms: (1) the physical active learning (PAL) intervention arm, (2) the don't worry-be happy (DWBH) intervention arm, or (3) current practice (control arm). All schools participating in ScIM had two or three mandatory PE-lessons per week. Schools in the two intervention arms added two hours of PA and PE to the class schedule each week. PA was assessed by accelerometers at baseline, midpoint and at the end of the intervention. All other variables were tested at baseline and at the end of the intervention. The measures included cardiorespiratory fitness, muscle strength, mental health (general mental health, quality of life and self-perception) academic performance (standardized national tests in reading and numeracy) and learning environment. Qualitative interviews were performed with students, teachers and school management to obtain an in-depth understanding of pedagogical processes taking place during the intervention.

Discussion: This study will inform what effect two added hours of PA during the school week can have on adolescents' PA levels, their health, academic performance and learning environment. Further, the study will add valuable information if the two PA interventions will generate different effects on important factors for learning and health.

Trial registration: Clinicaltrials.gov ID nr: NCT03817047. Registered 01/25/2019 'retrospectively registered'

\section{Background}

It is well known that participation in regular physical activity (PA) is important for both physical and mental health [1]. Among adolescents, cross-sectional and prospective studies have reported inverse associations between device measured PA, adiposity and cardiometabolic risk factors [2-4]. PA is also associated with mental health, when mental health is restricted to the outcomes of depression, anxiety, self-esteem and cognitive functioning $[5,6]$. However, levels of PA decline markedly during adolescence $[7,8]$, and a worrying high number of adolescents do not meet recommended levels of PA to achieve 
health benefits. Data from national surveillance studies in Norway shows that whilst approximately $90 \%$ of six-year-olds meet national PA recommendations of at least 60 minutes of moderate-to-vigorous intensity physical activity (MVPA) on average per day, this is reduced to $50 \%$ when the population reach 15-years of age [7, 9]. A high percentage of adolescents do also self-report mental disorders, with the most common being typical stress symptoms [10]. The extent of self-reported depressive symptoms have gradually increased during recent years, and the problems appear to be more pronounced in girls than in boys [10].

The school has been considered as an ideal environment for population-based PA interventions, as no other institution has as much influence on children during the first two decades of life [11]. Several school-based interventions have been implemented aiming to increase PA level among young people. A recently published meta-analysis did, however, show that school-based PA interventions have been inefficient at increasing children's accelerometer-assessed daily time spent in MVPA [12]. Nevertheless, some school-based PA interventions have reported to reduce adiposity and improve cardiometabolic risk factors in children participating in the intervention compared to those in the control group $[13,14]$. Further, a newly published review of reviews concluded that there is strong evidence for a casual association between PA and cognitive functioning, and partial evidence for depression [5]. Over the last years, increased interest has been shown for the topic of PA and academic performance in children and adolescents. Some studies shows beneficial effect of PA interventions on academic performance in children [15], but the results are inconclusive $[5,15,16]$.

The majority of school-based PA interventions are implemented among children in primary school $[14,17$, 18], and there is a lack of PA-interventions among adolescents in lower secondary school. Adolescence is considered a crucial period of life, and it is characterized by major biological, psychological and social challenges. This phase can bring up issues of independence and self-identity, and peer groups and appearance increase in perceived importance. Adolescents are no more children, and PA interventions that are effective in children might not be transferrable to adolescents.

School in motion (ScIM) is a school-based PA intervention carried out over one school year, in a sample of 14-year-old girls and boys attending lower secondary school in Norway. The main aim of this study was to investigate whether adding two extra hours of PA and PE weekly to the schedule lead to increases in accelerometer assessed PA level among the participants in the intervention groups compared to the control group.

Our secondary aims were to investigate the intervention effects on time spent in MVPA, time spent sedentary, muscle strength, cardiorespiratory fitness, mental health (including overall psychosocial problems and strengths, health-related quality of life, self-concept and self-esteem, and symptoms of anxiety and depression), academic performance and learning environment. Factors affecting implementation were also studied.

\section{Methods/design}




\section{Study design, study population and inclusion criteria}

ScIM is a multicenter, school-based, three-arm cluster randomized controlled trial (RCT) recruiting ninth graders from lower secondary schools in Norway. The intervention was implemented during the school year 2017-18 and conducted by four collaborating study partners (Norwegian School of Sport Sciences, Western Norway University of Applied Sciences, University of Agder, and University of Stavanger). A random sample of lower secondary schools located in municipalities in the geographical area near the four study partners were included. In the selection of schools, population density was considered; consequently, a different number of schools were included from each of the four geographical areas.

Private schools, designated special schools and schools with less than 25 adolescents in ninth grade were excluded from the study sample. Schools that already worked systematically with PA as an integrated part of the school day were also excluded. The recruitment of schools started in January 2017. First, County Governors were informed about the project by information posted on their web page. We then contacted school owners in the different municipalities to get permission to contact the principals of the schools that should be invited to participate. If the school owner approved, the letter of invitation was sent to the school's principal. This was followed by a phone call from the research team to give the principal and school management further information about the project and answering any questions they might have. A visit to the school was then scheduled to present the project in its entirety. Schools that wanted to participate in the study returned a signed consent form. Information meetings was held with all teachers at the intervention schools, and teachers involved in implementation of the intervention received further information regarding the intervention components.

A total of 103 schools were invited to participate. Of these, 30 schools returned the signed consent form and were included. A neutral third party randomly assigned the schools (clusters) to one of the two intervention arms or the control arm. The randomization was stratified by study center to assure that there were schools in all three study arms at all four study locations. Ten schools were randomized to the intervention arm called "Physical Active Learning" (PAL), ten schools to the intervention arm called "Don't worry, Be happy" (DWBH), and ten schools were randomized to the control arm. One of the included schools in the control arm withdrew from the study after the randomization procedure but prior to baseline testing, consequently, nine schools were left in the control arm. Blinding of participants and schools were not possible due to the contents of the intervention.

The flow diagram is presented in Figure 1. All adolescents in ninth grade (14-year-olds) within the 29 participating schools were eligible to participate $(n=2,733)$. Adolescents and their parents received detailed written information about ScIM, and they were invited to a school meeting outlining the study. A total of 2,084 adolescents returned the consent form signed by a parent/guardian, yielding a participation rate of $76 \%$. Three months into the intervention, one of the schools in the DWBH-intervention arm withdrew from the study due to practical reasons.

(Insert figure 1 here) 


\section{The ScIM intervention}

All schools participating in ScIM had two or three scheduled mandatory PE-lessons per week as part of their curriculum. Schools in the two intervention arms added one hour of PA and one hour of PE to the class schedule per week. This was done by redistributing five percent of time from other subjects in the curriculum to PA (corresponds to 60 minutes of PA per week), while the last 60 minutes were added to the classes' schedule each week. The schools received financial resources from The Norwegian Directorate for Education and Training to account for the increased expenses for the schools. The amount received by each lower secondary school was based on the number of students attending the school.

To optimize adherence, the intervention components were established as part of the mandatory school curriculum for all adolescents attending the schools in both intervention arms. The two intervention arms and the control arm are described below.

The PAL-intervention arm included three additional components of PA per week:

- PE (60 minutes): One weekly additional lesson of PE. The activities taught in this lesson were in line with the curriculum, and the PE teacher planned and taught the class.

- Physical active learning (30 minutes): During this session play-based activities were integrated in regular subjects (i.e. maths, English, Norwegian). The aim was to increase the students' PA level while improving their academic performance. The PAL component should preferably be carried out on days without PE-lessons. The classroom teacher of the current subject planned and taught the session.

- PA session (30 minutes): This session included a variety of activities preferably with at least moderate intensity, with an emphasis of activities that were enjoyable, giving the adolescents a feeling of pleasure and well-being. The PA sessions often took place outdoors and without the adolescent changing clothes. A classroom teacher or a PE teacher planned and led the activity.

The DWBH-intervention arm included two extra PA components each week:

- Be happy-class (60 minutes): In this session the adolescents performed activities in self-organized groups of at least three students, developed according to the individual's activity preferences (groups were made of individuals across regular classes). The chosen activities could be traditional sports, lifestyle sports, dancing, out-door recreation, drama etc. and was performed inside or outside the school. PE-teachers (often several teachers based on the size of the class) were present to support the students if necessary.

- Don't worry class (60 minutes): This was a PE lesson, and was conducted in the adolescents' regular classes, however, it was organized and led by the students. The students practiced their Be Happyactivities, or they introduced their class peers to their Be Happy-activity. A PE-teacher was present to support the students if necessary. 
During the first week, the students were introduced to the key features of the intervention. The students were told to organize Be Happy groups based on activity preferences. When the groups were established, every group had to hand in a document that showed:

1. three aims to govern the group (e.g. we do street dance and will develop each other, be friends and have fun with dance),

2. one major aim for the next six months (e.g. we will develop enough knowledge about yoga to be able to teach yoga in our PE class),

3. a management structure (e.g. leadership will switch according to a plan),

4. a strategy for impending conflicts (e.g. we must dare to address what may be difficult. If we do not fix it, we will ask the teacher for help), and

5. routines for registration of attendance (e.g. we will take pictures and send to the teacher).

A teacher had to approve the document before the group could start their activities.

The schools in the control arm continued current practice and were asked not to make changes to increase PA or PE during the intervention period. In order to prevent changes, the intervention was offered to the schools in the control arm when the intervention period was finished.

\section{Theoretical framework}

The ScIM-intervention is based on a socioecological framework, that understands the complex interplay between the many personal and environmental influences on behavior [19]. In short, the socioecological approach recognizes proximal individual and social factors and several distal determinants for behavior change such as individual factors (e.g. self-esteem, attitudes), social relationships (e.g. family, friends), the physical environment (e.g. schools, walkability), and policies (e.g. curriculum, schedules) as different levels of impact. Change at all levels is necessary to achieve lasting positive change in health behavior. In terms of individual and social factors, the PAL-intervention builds on Harter's competence motivation theory [20], Bandura's social-cognitive theory [21] and Ryan \& Deci's self-determination theory [22]. The theoretical rationale is thought to function as a mediating structure between intervention strategies and outcomes.

The primary focus of the DWBH-intervention arm was to promote friendship through PA and vice versa. The model was anchored to an integrative relational developmental systems (RDS) approach to human development [23], theories on Positive Youth Development (PYD) [24] and the concept of Positive Movement Experiences (PME) [25].

According to RDS-theories on human development, different subsystems of variables in humans are related to each other at different organizational levels (e.g. microbiology, cognitive function, family, friends and culture). Thus, when intervening the everyday life of adolescents these subsystems should be seen as interpenetrating dynamic dimensions and a PA intervention should be seen as mental and social 
as well as physical. In addition, diversity among adolescents involved represents a significant issue meaning that effects of a PA intervention will rely on the adolescents' relational experience of meaning and relevance in the new movement context (intervention) and not on the activity dose per se. An intervention hits as many developmental trajectories as there are participants and every participant will experience the interaction going on in the intervention context differently. Therefore, such interventions cannot rely on a "one size fits all" approach.

According to the RDS perspective school-based interventions should promote individual-context relations that are mutually beneficial for everyone involved. According to Agans and colleagues [25] it is possible for all individuals to have PME if the characteristics of the individual and the characteristics of the context are aligned in such a way as to produce mutually beneficial relations among all students and teachers involved. From the perspective of PYD no one but the adolescents are capable to build these mutually beneficial person-context relations. According to theories on PYD all youth do have strengths, and these strengths need to be identified and acknowledged to promote healthy development. This view of adolescents regards them as resources to be developed, not problems to be managed [26].

\section{Outcome measures}

All participants were tested in an identical set of outcome measures at baseline, and approximately 12 months after the baseline measures, when the participants were at the end of ninth grade and during the last phase of the intervention. Physical activity was also assessed midpoint during the intervention. Data were collected at the participating schools in a gymnasium or in the classroom. All research personnel were trained by members of the research team. Figure 2 provides an overview of the study time line and the data collection intervals.

(Insert figure 2)

\section{Physical activity level (primary outcome)}

PA was assessed by triaxial accelerometry (ActiGraph GT3X+, LLC, Pensacola, Florida, USA). The adolescents were instructed to wear the accelerometer on the right hip for seven consecutive days at all times, except during water activities or while sleeping. All raw accelerometer files were processed and analyzed using specifically developed and commercially available software (KineSoft version 3.3.20, Saskatchewan, Canada). A wear-time of $\geq 480 \mathrm{~min} /$ day was applied as a criterion for a valid day. Periods of $\geq 20$ min of zero counts were defined as non-wear time [27]. The number of 'valid days' vary depending on the analyses performed. Outcomes for PA are total PA level averaged per day (mean counts per minute [CPM]), time spent sedentary ( $\mathrm{min} /$ day), and time spent in different PA intensities ( $\mathrm{min} /$ day). Sedentary time was defined as all activity $<100$ CPM, this cut-point has shown to provide a realistic estimate of the time adolescents spend doing sedentary activities [28]. MVPA was defined as all activity $>2000$ CPM, this cut-point was developed for the European Youth Heart Study and is equivalent to a 
walking speed of adolescents of $>4 \mathrm{~km} / \mathrm{h}$ [2]. All analyses were based on accumulation of data over 10 second epochs.

\section{Cardiorespiratory fitness}

Cardiorespiratory fitness was measured with the Andersen-test, which is an intermittent running field test [29]. The Andersen-test was administered as per standard procedures indoors on a wooden or rubber floor, however, due to different sizes of available indoor facilities we standardized the length to 16 meters (original protocol 20 meters). All adolescents were tested in groups of 6-12 individuals. They ran from one line to another line 16 meter apart in an intermittent to-and-from movement for a total of 10 minutes, with 15 -seconds work periods and 15-seconds breaks standing still. We recorded the distance covered during the test in meter as a proxy for cardiorespiratory fitness.

\section{Muscle strength}

Muscle strength (i.e. endurance, isometric and explosive strength) was measured using reliable and validated selected tests from the Eurofit test battery [30]: 1) Upper limb strength - handgrip strength was measured using a hand dynamometer (Baseline ${ }^{\circledR}$ Hydraulic Hand Dynamometer, Elmsford, NY, USA); 2) Explosive strength in the lower body was measured using a standing broad jump test; and 3) Abdominal muscle endurance was tested using a sit-up test (number of correctly performed sit-ups within 30 seconds). The result from the muscle strength tests were recorded both individually and as a composite z-score for analyses.

\section{Anthropometry}

Body mass (weight; $0.1 \mathrm{~kg}$ ) was measured using an electronic scale (Seca 899, SECA GmbH, Hamburg, Germany) with individuals wearing light clothing. Stature (height; $0.1 \mathrm{~cm}$ ) was measured using a portable stadiometer (Seca $213 \mathrm{GmbH}$, Hamburg, Germany). During the measurement the individual was facing forward, with shoes removed. In the analyses, $0.6 \mathrm{~kg}$ (light clothing) or $1.5 \mathrm{~kg}$ (more heavy clothing) was subtracted from each person's weight to account for the clothing. We calculated body mass index $\left(\mathrm{kg} \cdot \mathrm{m}^{-2}\right)$ as weight $(\mathrm{kg})$ divided by the height squared $\left(\mathrm{m}^{2}\right)$. Waist circumference was measured with an ergonomic circumference measuring tape (Seca $201 \mathrm{GmbH}$, Hamburg, Germany). The measure was taken at the midway between the lower rib and iliac crest with the adolescent's abdomen relaxed at the end of a gentle expiration. The individual stood with arms hanging slightly away from the body. Two measurements were collected from each individual. If the difference between measures was a greater than one $\mathrm{cm}$, a third measurement was obtained; and the mean of two closest measurements was used for analyses. 


\section{Socioeconomic status and birth country}

The highest education level of the participant's parents was used as a proxy for socioeconomic status (SES). To obtain information regarding the parents' education level, our database was linked to registry data collected by Statistics Norway. Four SES groups were computed: low (primary school, lower secondary school, vocational high school), middle (secondary school/high school), middle high (undergraduate degree) and high (graduate degree). We also used registry data collected by Statistics Norway to receive information regarding the birth country of participants' and their parents.

\section{Mental health (SDQ, Kidscreen, Harter, Hopkins)}

Overall psychosocial problems and strengths was assessed with the Strength and Difficulties Questionnaire (SDQ). This is a screening instrument consisting of 25 items equally divided across five scales measuring emotional symptoms, conduct problems, hyperactivity-inattention, peer problems, and prosocial behavior [31].

Adolescent's health-related quality of life (QoL) was self-reported using the Kidscreen-27 questionnaire [32]. The instrument consists of 27 items covering the following five QoL dimensions: 1) physical wellbeing (5 items); 2 ) psychological well-being ( 7 items); 3 ) parents/guardians relations \& autonomy (7 items); 4) social support \& peers (4 items); and 5) school environment (5 items).

We used Harter's Self-perception Profile for Adolescents (SPPA) to assess the adolescent's domain specific self-evaluation of competence or adequacy [33]. The instrument consists of seven subscales covering the following domains: 1) scholastic competence, 2) social competence, 3) athletic competence, 4) physical appearance, 5) job competence, 6) close friendship, and 7) romantic appeal.

Symptoms of anxiety and depression were assessed by the short version of Hopkins Symptom Checklist (HSCL-10) [34]. HSCL-10 consists of 10 symptoms or problems that people sometimes have in which adolescents answered how much the symptoms have bothered or distressed them during the last week.

\section{Academic performance}

Academic performance in reading and numeracy were measured using specific standardized Norwegian National tests designed and administrated by The Norwegian Directorate for Education and Training [35]. The national test in reading measured the extent to which the individuals' reading skills are consistent with the descriptions of reading as basic skills in the curriculum, while the national test in numeracy measures the extent to which individuals' competency complies with the descriptions of numeracy as the basic skill of the curriculum. The National tests are designed for the students to show whether they have the basic skills in reading or numeracy that is necessary to achieve the competence goals in the subjects, 
and it is not a test in the Norwegian or mathematic subject per se. The National tests are extensively validity and reliability tested by The Norwegian Directorate for Education and Training.

\section{Learning environment}

The Classroom Climate Scale was used to assess learning environment [36]. This instrument consists of 22 questions related to intrinsic and extrinsic motivation, anticipation and teacher-student relations. In addition, three questions were asked related to the learning environment at school in general, in the classroom and during recess. The answers to the various questions were summarized individually.

\section{Physical education}

Three instruments were used to assess the adolescent's experience of PE-lessons: 1) change in satisfaction of basic psychological needs in the subject was assessed by Basic Psychological Needs in Exercise Scale (BPNES) [37]; 2) emotional responses to the subject was assessed by the Basic Emotions Trait Test (BETT) [38]; and 3) eagerness to join the subject was assessed by Eagerness for Physical Activity Scale (EPAS) [39].

\section{Qualitative study}

In the initial phase of the implementation, teachers at the intervention schools completed a short questionnaire to assess the school's readiness to change. Towards the end of the intervention period, four random schools from each intervention arm were invited to participate in a qualitative study where the aim was to investigate the following questions: a) what factors influenced the implementation of the intervention, and, b) how did the students and teachers receive the intervention? A semi-structured interview guide was developed to answer these questions, and interviews were conducted with principals, teachers and students. The interviews with principals and teachers were performed as individual interviews, as was considered a suitable method for investigating how the principals and teachers perceived, led and facilitated the intervention. Among the adolescents, on the other hand, focus groups were used as this can help reduce the power imbalance between an adult interviewer and young informants [40]. In the latter interviews, the aim was to obtain common reflections and descriptions of how the various intervention components were received and integrated into the adolescents' school life and the teachers' practice. All participates provided written consent to participate in the qualitative study.

\section{Adherence}

During the intervention period, teachers at the intervention schools documented the extent to which the intervention was implemented (dose) as intended through a weekly online form. The report described activities performed throughout the school day, the intensity of the activities (one a 1 to 3 scale) and the 
number of minutes of the PA sessions. Researchers from the project group visited each intervention school twice per semester to assess the quality of the implementation (fidelity). To improve the implementation of the intervention, teachers from the intervention schools were invited to the coordinating test center to share their experience with the implementation of the intervention. Two webinars were also organized for the teachers during the intervention period, and participation was voluntarily.

\section{Statistical considerations/Statistical methods}

\section{Power calculations/Sample size and power}

The ScIM study was designed to detect a difference in total PA level of $7 \%(49 \mathrm{cpm})$ between the participants in the intervention arms and the control arm. We assumed a standard deviation (SD) of 150 cpm, a power of $90 \%$, a significance of 0.05 , leading to 492 individuals in each group. To allow for $20 \%$ loss to follow-up we needed 590 individuals in each group. Further, we needed a minimum of ten clusters per study arm, consequently we aimed to recruit clusters and individuals until we had at least ten clusters and 590 individuals per study arm.

\section{Plan for analysis}

Data will be described with suitable measures of central tendency and variability, along with confidence intervals. Mixed models with school as random effect, adjusted for class, individual and baseline values, will be used to investigate the difference in the different variables when comparing the students in the two intervention groups with the students in the control group. By building up a mixed model, all participants who have data at baseline and everyone who has data at the post- test will be included, and thus all data will be utilized. A two-sided $p$-value $<0.05$ will be considered statistically significant.

The analysis from the qualitative study is based on a thematic content analysis [45]. The analysis work starts with the sound recordings being listened to repeatedly while immediate reflections are written down. Then all interviews will be transcribed and coded descriptively. The content will be discussed and organized by the researchers in collaboration, and a thematic framework will be identified.

\section{Ethical perspectives}

The project was reviewed by the Regional Committee for Medical and Health Research Ethics (REK) in Norway, who according to the Act on medical and health research (the Health Research Act 2008) concluded that the study did not require full review by REK. The study was approved by the Norwegian Centre for Research Data. The study was conducted in accordance with the principles set forth by the Helsinki declaration. Written informed consent from the participants and their parents or caretakers was 
obtained prior to the data collection. Reporting are anonymous, and individual participants cannot be identified in any published materials. The design, conduct, and reporting of this trial adhere to the CONSORT statement [41].

\section{Discussion}

This paper describes the ScIM study protocol, a school-based PA intervention aiming to increase PA levels of 14-year-olds attending lower secondary schools. ScIM will provide novel information on the effectiveness of school-based PA interventions on PA-levels, physical and mental health, academic performance and learning environment in an adolescent population.

A strength of the present study is that the ScIM intervention was designed to be easily adapted in a "reallife setting". The intervention was delivered by teachers at the schools with support from the research group, and none of the intervention components required expensive equipment. To secure a successful implementation of the ScIM intervention, some key elements were considered to be of importance [42]. First, the school management had to feel committed to participate in the study as they played a crucial role in the successful implementation of health promotion measures both as initiators and as responsible organizational facilitators [43]. We therefore conducted several meetings with the school management so they could get extensive information about the project. It was also required that the intervention components had to be formally implemented into the schools' plans and curriculums. Second, the project had to be accepted and supported by the school personnel to be performed as intended. The teachers had to feel the obligation to and be willing to conduct the intervention components as described and at the same time develop ownership to the project. In order to do so, the teachers had to perceive the project as rewarding and feasible. Through information meetings and training of teachers, we aimed to improve adherence to the program from key personnel. Time constraints has been identified as a barrier to implementation of school-based PA initiatives [42]. To avoid overload for the teachers, teachers needed time to prepare and deliver the intervention components. Practical advices for organization and performance were available for the teachers, however, optional to use. We made a 'tool-kit' of different activities that the teachers could use and include in the different intervention components. The activities were based on feedback from teachers and students, and already existing pedagogical material. A password protected web-page was established to make the tools available for the intervention schools. These mentioned key elements had the potential to create a common understanding of the premises of the project and thus create a mutual commitment to the implementation of the program. We allowed for a certain degree of local adaptation of the intervention to ensure implementation. The schools in the PALintervention arm could, for instance, divide the weekly 30-minute physical active learning session into two 15-minute sessions if that was more feasible. At the same time there was a need to limit local variation from a research perspective.

The two intervention arms were pilot tested during the school year 2016-17 in seven lower secondary schools (including approximately 700 students). Based on the pilot study, some adjustments were made to both intervention arms. For instance, a daily five-minute PA break was originally included in the PAL- 
intervention. This component has often been successfully implemented in PA interventions among children in primary schools [44]. However, both teachers and students in the pilot study reported that the five-minute break did not work as intended, and the component was were excluded from the PALintervention model. The adjustment made to both intervention programs following the pilot study tailored the intervention to better reach the target group.

There is a lack of knowledge regarding which components of PA interventions are most important to increase adolescents PA level [41]. In the PAL-intervention, the intensity and the total dose of PA was of importance. Also, the teachers played a crucial role in the delivery of the intervention. In the DWBHintervention, the emphasis was on the adolescents themselves as they were in charge of the planning and execution of the activities. The participants formed activity groups based on their activity preferences, and the social relations in the groups were more important than the dose and intensity of the activities. By assessing the effect on the different outcome measures comparing the two intervention arms with the control arm, we aim to increase the knowledge about the effectiveness of two different school-based interventions on adolescent's physical activity levels. We will, however, not be able to disentangle the effect of the different components within each intervention arm.

In this cluster randomized controlled trial, we included adolescents from 29 lower secondary schools from different parts of the country, schools of different sizes and located both in urban and more rural areas. This enabled us to implement the two PA interventions under different circumstances, meaning that if it proves acceptable it is likely to be transferable to most schools in Norway and similar countries.

\section{Conclusion}

ScIM was a one-year cluster RCT including 2084 adolescents from 29 lower secondary schools from both rural and urban parts of the Norway. The study will inform us what effects two added hours of PA during the school week can have on adolescents' PA level, mental and physical health, academic performance and learning environment. Further, the study will add valuable information if the two different PA interventions will generate different effects on important factors for learning and health.

\section{Declarations}

- Ethics approval and consent to participate: The project was reviewed by the Regional Committee for Medical and Health Research Ethics (REK) in Norway, who according to the Act on medical and health research (the Health Research Act 2008) concluded that the study did not require full review by REK. The study was approved by the Norwegian Centre for Research Data. Written informed consent from the participants and their parents or caretakers was obtained prior to the data collection

- Consent for publication: Not applicable

- Availability of data and material: The datasets generated and/or analyzed during the current study are not publicly available as publications are planned but are available from the corresponding 
author on reasonable request.

- Competing interests: The authors declare that they have no competing interests.

- Funding: The study was funded by grants from the Norwegian Directorate for Education and Training.

- Authors' contributions: Each author has contributed to the conception and design of the work. All authors participated in writing of the paper and approved the final version.

- Acknowledgements: ScIM Study group: Øystein Lerum (Western Norway University of Applied Sciences); Lena Malnes Hansen (University of Agder); Tommy Haugen (University of Agder); Eva Leibinger (University of Stavanger); Andreas Åvitsland (University of Stavanger)

\section{Abbreviations}

DWBH

Don't worry - be happy

MVPA

Moderate-to-vigorous intensity physical activity

PA

Physical activity

PAL

Physical active learning

PE

Physical education

PME

Positive Movement Experiences

PYD

Positive Youth Development

RCT

Randomized controlled trial

RDS

Relational developmental systems

ScIM

School in motion

\section{References}

1. Janssen I, Leblanc AG. Systematic review of the health benefits of physical activity and fitness in school-aged children and youth. Int J Behav Nutr Phys Act. 2010;7:40.

2. Andersen LB, Harro M, Sardinha LB, Froberg K, Ekelund U, Brage S, Anderssen SA. Physical activity and clustered cardiovascular risk in children: a cross-sectional study (The European Youth Heart Study). Lancet. 2006;368;(9532):299-304. 
3. Ekelund U, Luan J, Sherar LB, Esliger DW, Griew P, Cooper A. Moderate to vigorous physical activity and sedentary time and cardiometabolic risk factors in children and adolescents. JAMA. 2012;307; (7):704-12.

4. Skrede T, Steene-Johannessen J, Anderssen SA, Resaland GK, Ekelund U. The prospective association between objectively measured sedentary time, moderate-to-vigorous physical activity and cardiometabolic risk factors in youth: a systematic review and meta-analysis. Obes Rev. 2018;20;(1):55-74.

5. Biddle SJH, Ciaccioni S, Thomas G, Vergeer I. Physical activity and mental health in children and adolescents: An updated review of reviews and an analysis of causality. Psychol Sport Exerc. 2019;42:146-55.

6. Ahn S, Fedewa AL. A meta-analysis of the relationship between children's physical activity and mental health. J Pediatr Psychol. 2011;36;(4):385-97.

7. Dalene KE, Anderssen SA, Andersen LB, Steene-Johannessen J, Ekelund U, Hansen BH, Kolle E. Secular and longitudinal physical activity changes in population-based samples of children and adolescents. Scand J Med Sci Sports. 2018;28;(1):161-71.

8. Cooper AR, Goodman A, Page AS, Sherar LB, Esliger DW, van Sluijs EM, Andersen LB, Anderssen S, Cardon G, Davey R et al. Objectively measured physical activity and sedentary time in youth: the International children's accelerometry database (ICAD). Int J Behav Nutr Phys Act. 2015;12:113.

9. Kolle E, Stokke JS, Hansen BH, Anderssen SA. Fysisk aktivitet blant 6-, 9- og 15-åringer i Norge. Resultater fra en kartlegging i 2011. Oslo, Norway; 2012.

10. Bakken A. Ungdata. Nasjonale resultater 2018. Oslo, Norway; 2018.

11. Dobbins M, Husson H, DeCorby K, LaRocca RL. School-based physical activity programs for promoting physical activity and fitness in children and adolescents aged 6 to 18 . Cochrane Database Syst Rev. 2013;(2):CD007651.

12. Love R, Adams J, van Sluijs EMF. Are school-based physical activity interventions effective and equitable? A meta-analysis of cluster randomized controlled trials with accelerometer-assessed activity. Obes Rev. 2019;20;(6):859-70.

13. Resaland GK, Anderssen SA, Holme IM, Mamen A, Andersen LB. Effects of a 2-year school-based daily physical activity intervention on cardiovascular disease risk factors: the Sogndal schoolintervention study. Scand J Med Sci Sports. 2011;21;(6):e122-31.

14. Kriemler S, Zahner L, Schindler C, Meyer U, Hartmann T, Hebestreit H, Brunner-La Rocca HP, van MW, Puder JJ. Effect of school based physical activity programme (KISS) on fitness and adiposity in primary schoolchildren: cluster randomised controlled trial. BMJ. 2010;340:c785.

15. Singh AS, Saliasi E, van den Berg V, Uijtdewilligen L, de Groot RHM, Jolles J, Andersen LB, Bailey R, Chang YK, Diamond A et al. Effects of physical activity interventions on cognitive and academic performance in children and adolescents: a novel combination of a systematic review and recommendations from an expert panel. Br J Sports Med. 2019;53;(10):640-7. 
16. Fedewa AL, Ahn S. The effects of physical activity and physical fitness on children's achievement and cognitive outcomes: a meta-analysis. Res Q Exerc Sport. 2011;82;(3):521-35.

17. Resaland GK, Aadland E, Moe VF, Aadland KN, Skrede T, Stavnsbo M, Suominen L, SteeneJohannessen J, Glosvik O, Andersen JR et al. Effects of physical activity on schoolchildren's academic performance: The Active Smarter Kids (ASK) cluster-randomized controlled trial. Prev Med. 2016;91:322-8.

18. Donnelly JE, Hillman CH, Greene JL, Hansen DM, Gibson CA, Sullivan DK, Poggio J, Mayo MS, Lambourne K, Szabo-Reed AN et al. Physical activity and academic achievement across the curriculum: Results from a 3-year cluster-randomized trial. Prev Med. 2017;99:140-5.

19. McLeroy KR, Bibeau D, Steckler A, Glanz K. An ecological perspective on health promotion programs. Health Educ Q. 1988;15;(4):351-77.

20. Harter S. Effectance motivation reconsidered: toward a developmental model. Human Development. 1978;21:34-64.

21. Bandura A. Social foundations of thought and action: A social cognitive theory. NJ: Englewood Cliffs; 1986.

22. Ryan R. Overview of self-determination theory. An organismic dialectical perspective. In: Handbook of self-determination research. edn. Edited by Ryan R. Rochester NY: The University of Rochester Press; 2002.

23. Lerner RM. Concepts and theories of human development 4th edn. New York: Routledge; 2018.

24. Lerner RM. Promoting positive human development and social justice: Integrating theory, research and application in contemporary developmental science. Int J Psychol. 2015;50;(3):165-73.

25. Agans JP, Safvenbom R, Davis JL, Bowers EP, Lerner RM. Positive Movement Experiences: Approaching the Study of Athletic Participation, Exercise, and Leisure Activity through Relational Developmental Systems Theory and the Concept of Embodiment. Adv Child Dev Behav. 2013;45:26186.

26. Roth J, Brooks-Gunn J, Murray L, Foster W. Promoting healthy adolescents: Synthesis of youth development program evaluations. J Res Adolescence. 1998;8;(4):423-59.

27. Esliger DW, Copeland JL, Barnes JD, Tremblay MS. Standardizing and Optimizing the Use of Accelerometer Data for Free-Living Physical Activity Monitoring. Journal of Physical Activity \& Health. 2005;2;(3):366.

28. Trost SG, Loprinzi PD, Moore R, Pfeiffer KA. Comparison of accelerometer cut points for predicting activity intensity in youth. Med Sci Sports Exerc. 2011;43;(7):1360-8.

29. Andersen LB, Andersen TE, Andersen E, Anderssen SA. An intermittent running test to estimate maximal oxygen uptake: the Andersen test. J Sports Med Phys Fitness. 2008;48;(4):434-7.

30. Council of Europe. Committee of Experts on Sports Research. Eurofit: handbook for the Eurofit tests of physical fitness. Strasbourg: Council of Europe, Committee for the Development of Sport; 1993. 
31. Goodman R. The strengths and difficulties questionnaire: A research note. Journal of Child Psychology and Psychiatry and Allied Disciplines. 1997;38;(5):581-6.

32. Ravens-Sieberer U, Auquier P, Erhart M, Gosch A, Rajmil L, Bruil J, Power M, Duer W, Cloetta B, Czemy $L$ et al. The KIDSCREEN-27 quality of life measure for children and adolescents: psychometric results from a cross-cultural survey in 13 European countries. Quality of Life Research. 2007;16;(8):1347-56.

33. Wichstrom L. Harter's Self-Perception Profile for Adolescents: reliability, validity, and evaluation of the question format. J Pers Assess. 1995;65;(1):100-16.

34. Strand BH, Dalgard OS, Tambs K, Rognerud M. Measuring the mental health status of the Norwegian population: A comparison of the instruments SCL-25, SCL-10, SCL-5 and MHI-5 (SF-36). Nord J Psychiat. 2003;57;(2):113-8.

35. The Norwegian Directorate for Education and Training. Kva er nasjonale prøver? https://www.udir.no/eksamen-og-prover/prover/nasjonale-prover/om-nasjonale-prover/. Accessed 18 Nov 2018.

36. Skaalvik EM, Skaalvik S. Elevenes opplevelse av skolen: sentrale sammenhenger og utvikling med alder. Spesialpedagogikk. 2009:36-47.

37. Vlachopoulos SP, Michailidou S. Development and Initial Validation of a Measure of Autonomy, Competence, and Relatedness in Exercise: The Basic Psychological Needs in Exercise Scale. Measurement in Physical Education and Exercise Science. 2006;10;(3):179-201.

38. Vitters $\varnothing$ J, Dyrdal GM, Røysamb E. Utilities and capabilities: A psychological account of the two concepts and their relation to the idea of a good life In: 2nd Workshop on Capabilities and Happiness. University of Milano, Bicocca, Italy; 2005.

39. Safvenbom R, Buch R, Aandstad A. Eagerness for Physical Activity Scale: Theoretical background and validation. Applied Developmental Science. 2017;21;(3):184-99.

40. Greene S, Hogan D. Researching children's experience: Approaches and methods. Sage; 2005.

41. Campbell MK, Elbourne DR, Altman DG. CONSORT statement: extension to cluster randomised trials. 2004;328;(7441):702-8.

42. Naylor PJ, Nettlefold L, Race D, Hoy C, Ashe MC, Wharf HJ, McKay HA. Implementation of school based physical activity interventions: a systematic review. Prev Med. 2015;72:95-115.

43. Tjomsland HE, Viig NG. Trivsel og læring i en Helsefremmende skole: Gyldendal Forlag; Oslo, 2015.

44. Donnelly JE, Hillman CH, Castelli D, Etnier JL, Lee S, Tomporowski P, Lambourne K, Szabo-Reed AN. Physical Activity, Fitness, Cognitive Function, and Academic Achievement in Children: A Systematic Review. Med Sci Sports Exerc. 2016;48;(6):1223-4. 




\section{Figure 1}

The consort flow diagram. Flow of schools and adolescents through the study. All numbers are schools [adolescents]. 




Figure 2

The study time line and the data collection intervals.

\section{Supplementary Files}

This is a list of supplementary files associated with this preprint. Click to download.

- CONSORT2010Checklist1.doc 